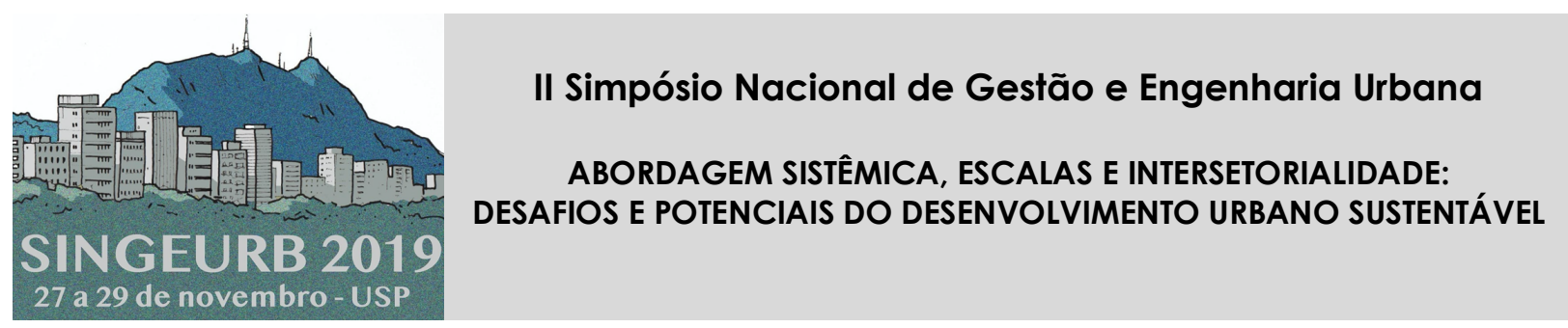

\title{
O impacto do processo de urbanização sobre a drenagem urbana: estudo de caso do Bairro São Pedro, Teresina, PI 1
}

\section{The impact of the urbanization process on urban drainage: a case study from the Bairro São Pedro - Teresina - PI}

\author{
Pessoa, Thiscianne Moraes'; Silveira, Ana Lucia Ribeiro Camillo da² \\ 1 Prefeitura Municipal de Teresina; Rua Honório de Paiva, 1421, Teresina, Piauí, \\ Brasil; thisciannempessoa@gmail.com \\ 2 Universidade Federal do Piauí; c_silveira@uol.com.br
}

\begin{abstract}
RESUMO
Teresina, capital do Piauí, tem sua zona urbana banhada por dois rios regionais, o Parnaíba e o Poti, e por diversos riachos e lagoas, responsáveis pela drenagem natural do território e promoção do escoamento das águas pluviais aos referidos rios. O processo de urbanização da capital vem estabelecendo uma relação conflituosa com essa característica natural. Tal fato tem contribuído para o agravamento dos problemas relacionados à drenagem urbana, como as inundações ribeirinhas, as enxurradas, os deslizamentos de encostas e a abertura de voçorocas. O estudo tem como objeto de investigação o bairro São Pedro, que sofre com enchentes periódicas. Com o objetivo de analisar a relação entre o processo de urbanização e a drenagem urbana, buscou-se compreender os principais condicionantes das enchentes periódicas vivenciadas pelos moradores. Esta pesquisa é um recorte de um estudo mais amplo sobre a gestão das águas pluviais da zona sul de Teresina, na qual o Bairro São Pedro encontra-se inserido, realizado na pesquisa de mestrado. Dentre os resultados alcançados, destaca-se que o tecido urbano do bairro nega por completo os elementos hídricos naturais e o relevo da região, apresentando-se assim, como o principal condicionante dos problemas relativos à drenagem urbana do bairro.
\end{abstract}

Palavras-chave: Processo de urbanização, drenagem urbana, Teresina.

\begin{abstract}
Teresina, capital of Piauí, has the urban zone bathed by two regional rivers, the Parnaíba river and the Poti river, besides its has a lot of streams and lagoons, responsible for the natural drainage of the territory, which promotes the flow of rainwater to the regional rivers. The process of urbanization of the capital has established a conflicting relationship with this natural characteristic. This fact has contributed to the aggravation of the problems related to the urban drainage, such as river floods, flash floods, landslides and gully openings. This paper studies the São Pedro neighborhood, which suffers from periodic flooding, with the objective of analyzing the relationship between the urbanization process and the urban drainage, in
\end{abstract}

\footnotetext{
${ }^{1}$ PESSOA, Thiscianne Moraes; SILVEIRA, Ana Lucia Ribeiro Camillo da. O impacto do processo de urbanização sobre a drenagem urbana: estudo de caso do Bairro São Pedro - Teresina/PI. In: II SIMPÓSIO NACIONAL DE GESTÃo E ENGENHARIA URBANA: SINGEURB, 2019, São Paulo. Anais... Porto Alegre: ANTAC, 2019.
} 
order to understand the main determinants of periodic flooding experienced by residents. This research is a summary of a broader study on the management of rainwater in the southern area of Teresina, in which the São Pedro neighborhood is inserted, carried out in a master's degree research. Among the results achieved, it is highlighted that the urban mesh of the neighborhood totally denies the natural water elements and the relief of the region, presenting itself as the main determinant of the problems related to the urban drainage in the neighborhood.

Keywords: Urbanization process, urban drainage, Teresina.

\section{INTRODUÇÃO}

Teresina, capital do Piauí, está localizada na porção Centro-Norte do estado e encontra-se inserida nas bacias hidrográficas difusas do Médio Parnaíba e do rio Poti. Devido à sua localização, dentro dessas duas bacias hidrográficas, a cidade apresenta, por todo seu território, riachos que são afluentes dos rios principais das bacias e lagoas nas áreas correspondentes aos leitos maiores dos rios Parnaíba e Poti (SILVEIRA; CARVALHO; PESSOA, 2016).

Outra característica importante a ser destacada, trata-se da questão climática. De acordo com a classificação de Koppen, Teresina possui o clima tropical megatérmico (SILVEIRA, 2007). As precipitações concentram-se nos quatro primeiros meses do ano, com cerca de $75,65 \%$ do regime pluviométrico, formado por chuvas torrenciais (SEMPLAN, 2015). A abordagem da gestão das águas pluviais no processo de urbanização da Cidade de Teresina é essencial diante dos condicionantes físicos e climáticos em que a cidade encontra-se inserida. No entanto, o que se percebe nas pesquisas já realizadas é uma negligência desse processo em relação aos seus corpos d'água.

Segundo Tucci (2006) e Tavanti (2011), desde a segunda metade do século XX, o grande crescimento populacional dos centros urbanos vem ocorrendo de forma desordenada, ocasionando uma série de problemas de ordem social e ambiental, englobando, assim, a questão da drenagem das águas pluviais. Dessa forma, a urbanização estabelece-se como um processo causador de enchentes urbanas, a partir do momento em que ela ocorre de maneira desordenada, pois a ocupação do espaço urbano em geral causa impactos ambientais, como explicam Tavani, Barbassa (2010):

(...) no balanço hídrico da bacia hidrológica, pois altera, principalmente as condições de infiltração e escoamento superficial; na geração de sedimentos, pois com a retirada da cobertura vegetal e com alterações na morfologia do terreno, criam-se condições para, dependendo do tipo de solo, o surgimento de processos erosivos; e a qualidade da água é afetada pela polvição difusa existente nas bacias urbanas, através principalmente, do primeiro fluxo de escoamento direto (...) (TAVANTI; BARBASSA, 2010, p.1).

Os inúmeros problemas ambientais das cidades brasileiras evidenciam a insuficiência do sistema de drenagem adotado, ressaltando que a "drenagem urbana já não é um assunto que possa ser tratado exclusivamente no âmbito técnico da engenharia" (POMPEU, 2000, p.15). Souza, V. (2017), considera que é preciso realizar uma mudança de paradigma, rompendo com a gestão de oferta, praticada pelo sistema de drenagem tradicional, por meio da gestão de canais, alcançando uma gestão de demanda, praticada pelo sistema de drenagem sustentável.

O objetivo do trabalho é analisar a relação que o processo de urbanização estabelece com a drenagem urbana, evidenciando se este apresenta-se como um condicionante das enchentes periódicas que ocorrem no bairro São Pedro, localizado na zona sul de Teresina.

\section{METODOLOGIA}

A presente pesquisa adotou como objeto de estudo o Bairro São Pedro, localizado na zona sul de Teresina, à margem do Rio Parnaíba (Figura 01). O bairro sofre com enchentes 
periódicas, fato ilustrado pelas manchetes elencadas a seguir: "Forte chuva cai em Teresina e traz transtornos e alagamentos em alguns pontos da cidade" (FORTE CHUVA CAl, 2019); "Fortes chuvas alagam casas e causam estragos em bairros de Teresina" (FORTES CHUVAS ALAGAM, 2018); "Moradores do bairro São Pedro ficam ilhados por conta da chuva do fim de semana" (MORADORES DO BAIRRO, 2014).

Figura 1 - Divisão de bairros de Teresina

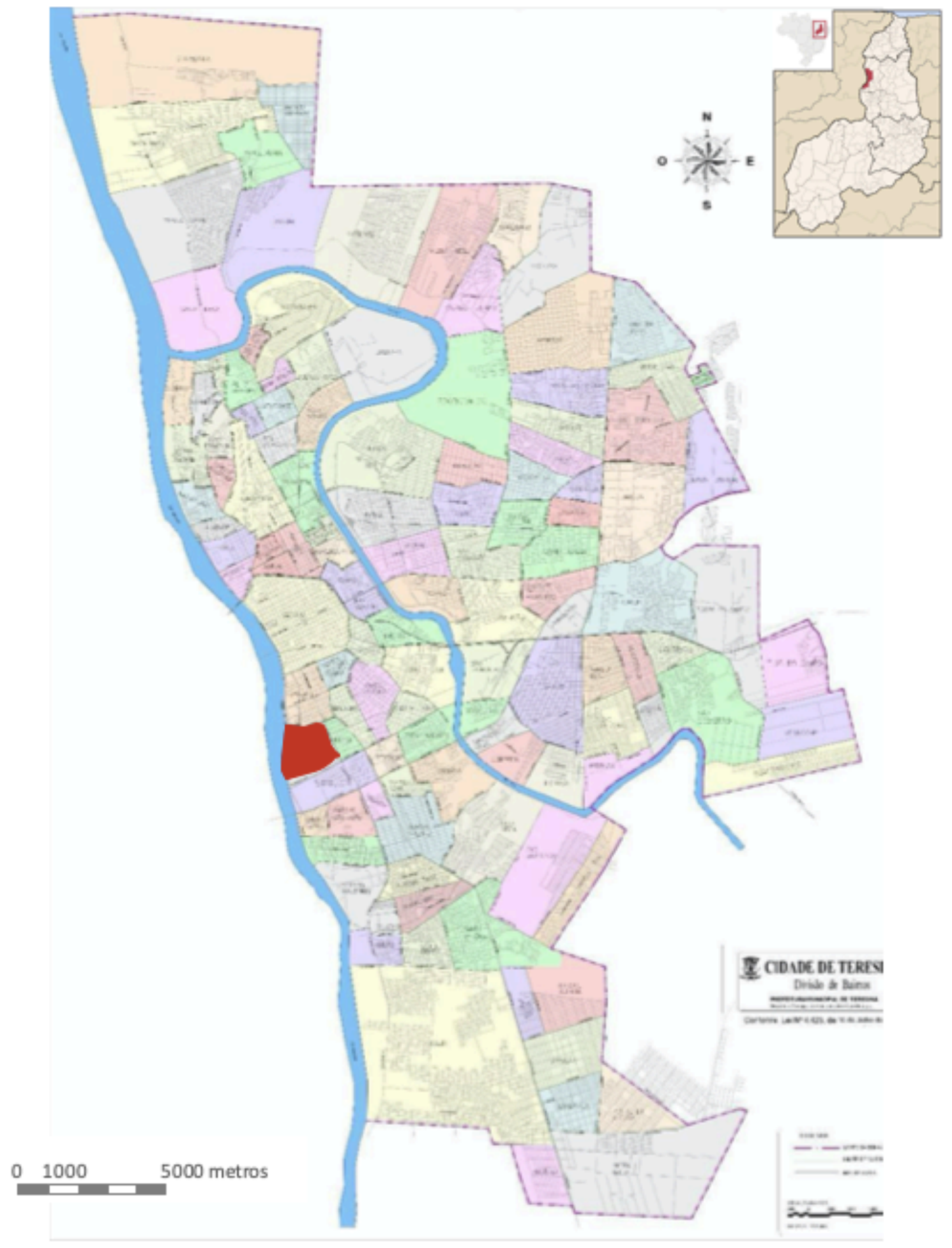

Legenda: Bairro São Pedro

Fonte: SEMPLAN (2013) 
A pesquisa foi desenvolvida a partir de três eixos de análise: o primeiro eixo analisado foi o processo de ocupação do Bairro São Pedro e do seu entorno, destacando-se o seu impacto sobre a drenagem natural; o segundo eixo refere-se às características físicas da área e o impacto que a urbanização tem sobre essas características; já o terceiro eixo buscou evidenciar o impacto que as leis municipais de uso e ocupação do solo vigentes causam sobre a área em estudo. A análise final dos dados levantados em cada um dos três eixos foi feita por meio da sobreposição desses dados, que permitiu a compreensão da origem dos problemas relativos à drenagem existentes na área.

\section{RESULTADOS}

\subsection{Processo de ocupação e sua influência na drenagem natural}

Teresina foi fundada em 1852, às margens do Rio Parnaíba, no planalto da Chapada do Corisco (FAÇANHA, 1998). O traçado inicial da cidade contava com 100 quarteirões (Figura 2), todos com a mesma dimensão, que abrigaram os primeiros prédios públicos, comerciais, residenciais, igrejas e algumas praças (LIMA, 2002). A partir da observação do mapa inicial da cidade, nota-se que o traçado urbano adotado desconsidera as características hidrográficas e topográficas da região, pois as ruas foram posicionadas perpendiculares ao leito do Rio Parnaíba, fato que ocasiona a elevação do escoamento superficial.

Figura 2 - Plano de Teresina, 1852

\section{Provtncia do Ollaranhão}

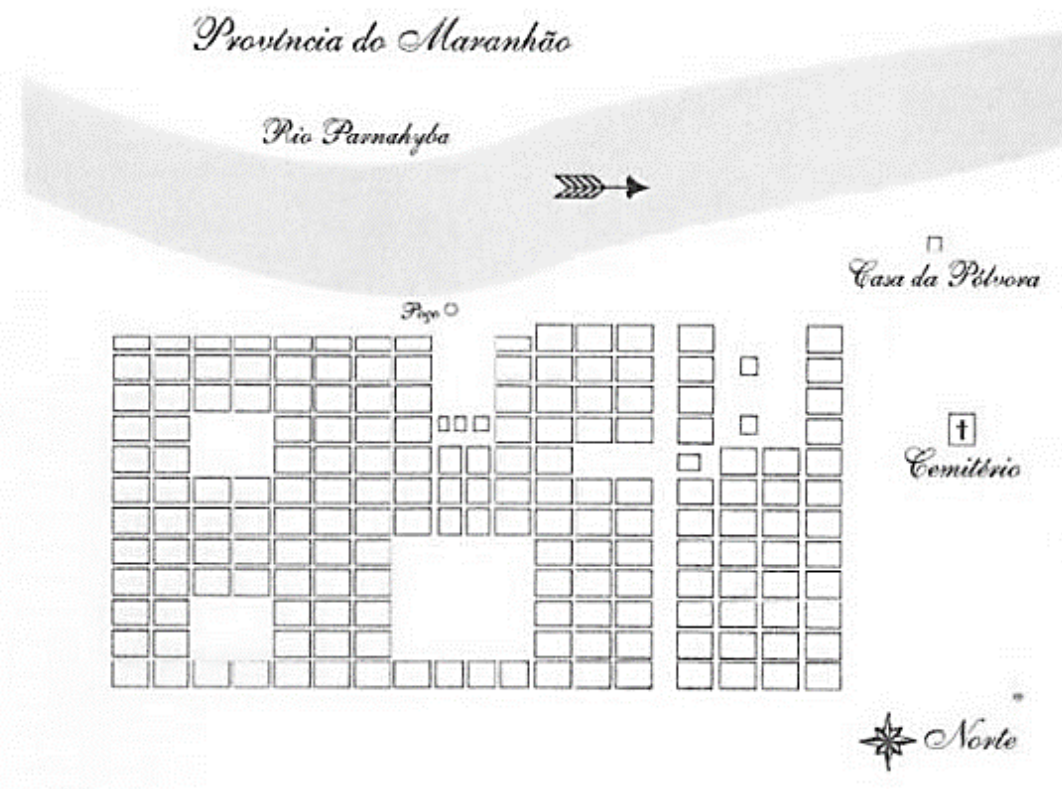

\section{Thia Yhly}

Fonte: SEMPLAN (1993) 
Por meio da análise da Figura 3, pode-se observar que o processo de ocupação da capital piauiense ocorreu tomando como referência o traçado inicial da cidade, havendo assim uma conformidade morfológica entre o Bairro Centro e os demais bairros adjacentes, que foram sendo ocupados com o passar dos anos. No que se refere ao Bairro São Pedro, a Figura 3 aponta que a consolidação do seu tecido urbano ocorreu ao longo de três décadas.

Figura 3 - Processo de ocupação do Bairro São Pedro e do seu entorno
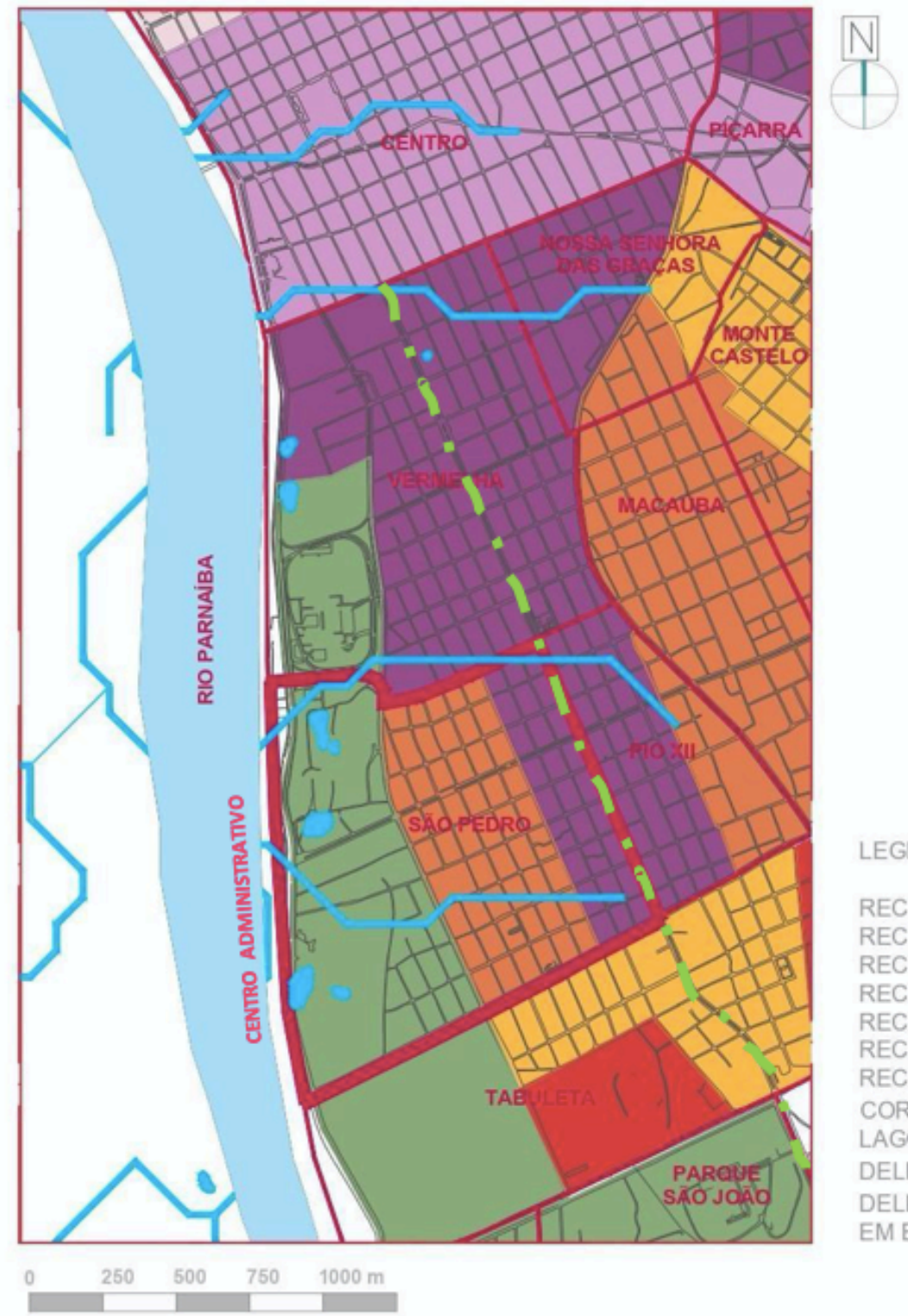

\section{LEGENDA:}

RECORTE TEMPORAL - 18501900 RECORTE TEMPORAL - 19001940. RECORTE TEMPORAL - 19411950 RECORTE TEMPORAL - 19511960 RECORTE TEMPORAL - 19611970 RECORTE TEMPORAL - 19711980. RECORTE TEMPORAL - 19912000 CORPOS D'ÁGUA.

LAGOAS.

DELIMITACÃ̃O DOS BAIRROS.

DELIMITAČÃO DO BAIRRO

EM ESTUDO.

Legenda: - " Av. Barão de Gurgueia

Fonte: PESSOA (2019) editado pelas autoras (2019)

O início do processo de ocupação ocorreu na década de 1940, condicionado pela presença da Av. Barão de Gurgueia, que se apresenta como um vetor de ocupação na direção sul. Lima (2002), explica que havia no entorno do centro urbano de Teresina diversas fazendas que começaram a ser incorporadas ao tecido urbano devido à ocupação das margens das estradas. Em relação à ocupação do Bairro São Pedro, destaca-se a construção da Estrada Nova (atual Av. Barão de Gurgueia), em 1877, que tinha como ponto de partida o Bairro Centro e seguia atravessando toda a região sul. 
Segundo Lima (2002), esse processo de ocupação ocorreu de forma desordenada, assumindo um traçado mais espontâneo quando comparado ao traçado da área central. $A$ autora destaca que, com isso, iniciaram-se os problemas ambientais em decorrência do conflito entre a ocupação do solo e a drenagem urbana. Dessa forma, "as lagoas e os vales dos riachos (chamados de "grotas" ou "grotões") foram sendo pavimentados, formando as primeiras "baixas" do relevo do sítio urbano, ainda sem ter um sistema adequado de galerias" (LIMA, 2002, p. 188). Acerca da Av. Barão de Gurgueia, ressalta-se a proximidade do seu leito carroçável ao leito maior do Rio Parnaíba, fato que acabou condicionando o aterramento de lagoas naturais localizadas à margem do rio para viabilizar o processo de ocupação urbana.

Na década de 1970, ocorreu o início da ocupação da área do Bairro São Pedro, localizada à margem direita do Rio Parnaíba, promovendo assim a consolidação do tecido urbano do bairro. A ocupação das áreas na margem do rio foi fomentada pela construção do Centro Administrativo do Piaú, projetado em 1979. Ressalta-se que o Centro Administrativo do Piauí foi locado em um terreno alagadiço (Figura 4) e, dessa forma, diversas lagoas naturais foram aterradas para a sua execução.

Figura 4 - Lagoa existente no canteiro de obras do Centro Administrativo do Governo do Estado, década de 1970

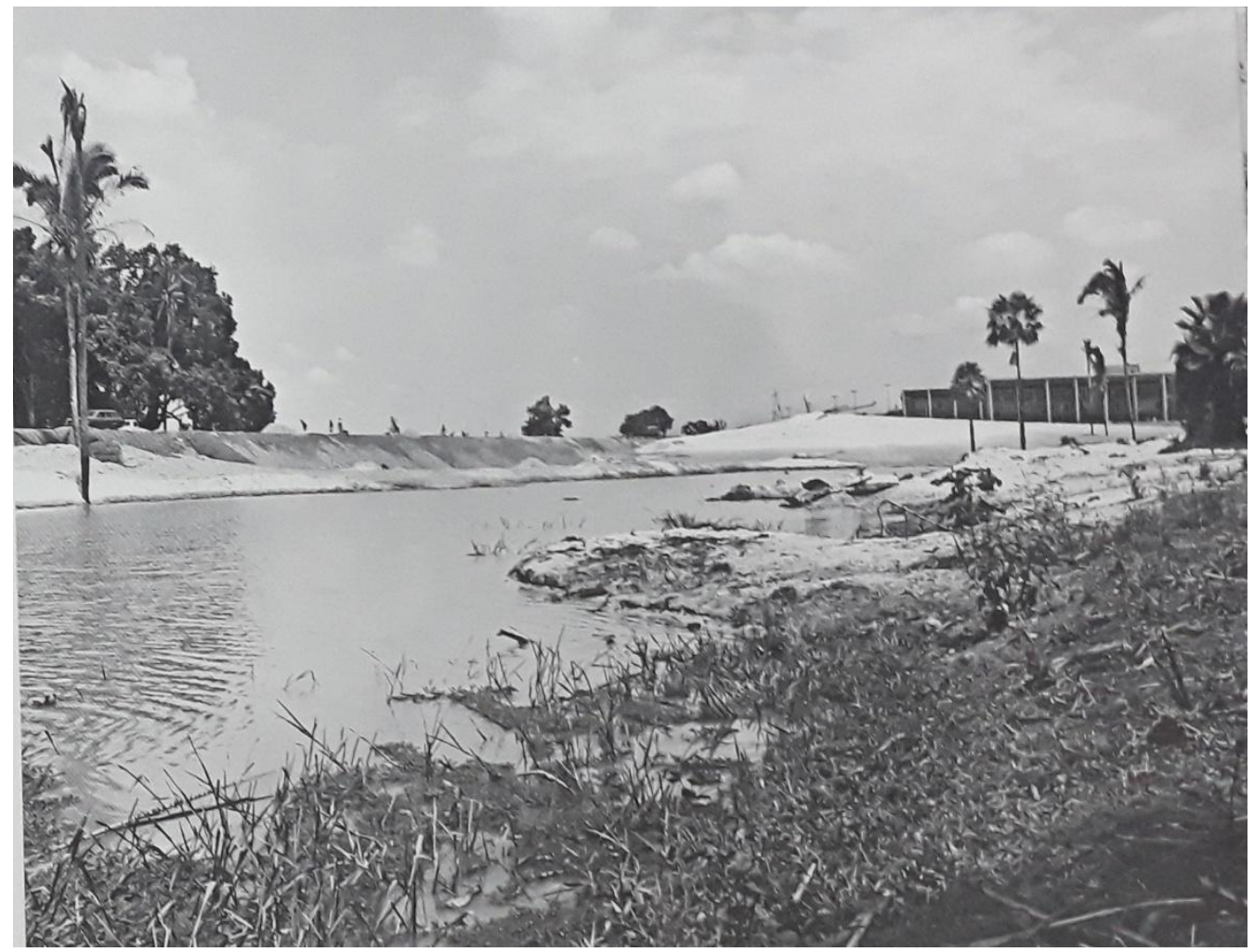

Fonte: SOUZA, P. (2017)

A Figura 3 permite observar que, dentro da área delimitada do Bairro São Pedro, existem corpos d'água, riachos intermitentes e lagoas naturais que não estabelecem nenhuma relação com o tecido urbano implantado no decorrer do tempo. Essa ausência de relação entre os corpos d'água e o tecido urbano ocorre também nas áreas no entorno do bairro. 0 tecido apenas sobrepõe-se sobre o local que antes pertencia a esses corpos d'água naturais, responsáveis pela drenagem da região.

\subsection{O relevo e os corpos d'água}

A Figura 5 evidencia a relação entre a topografia, os corpos d'água e o traçado viário no Bairro São Pedro e no seu entorno. Dessa forma, destaca-se por meio da análise desta, que o 
traçado viário não utiliza as curvas de nível como fator condicionante. Percebe-se também que a maior parte das vias é perpendicular às curvas de nível. Tavanti (2009) explica que as vias traçadas perpendiculares às curvas de nível aumentam a velocidade do escoamento superficial devido à sua maior declividade. Vieira, Teixeira e Lopes (2007) consideram que o aumento da velocidade de escoamento superficial, em decorrência do traçado inadequado das vias, ocasiona enxurradas que, por sua vez, provocam voçorocas, gerando uma série de transtornos para a população.

Figura 5 - Traçado viário, topografia e corpos d'água
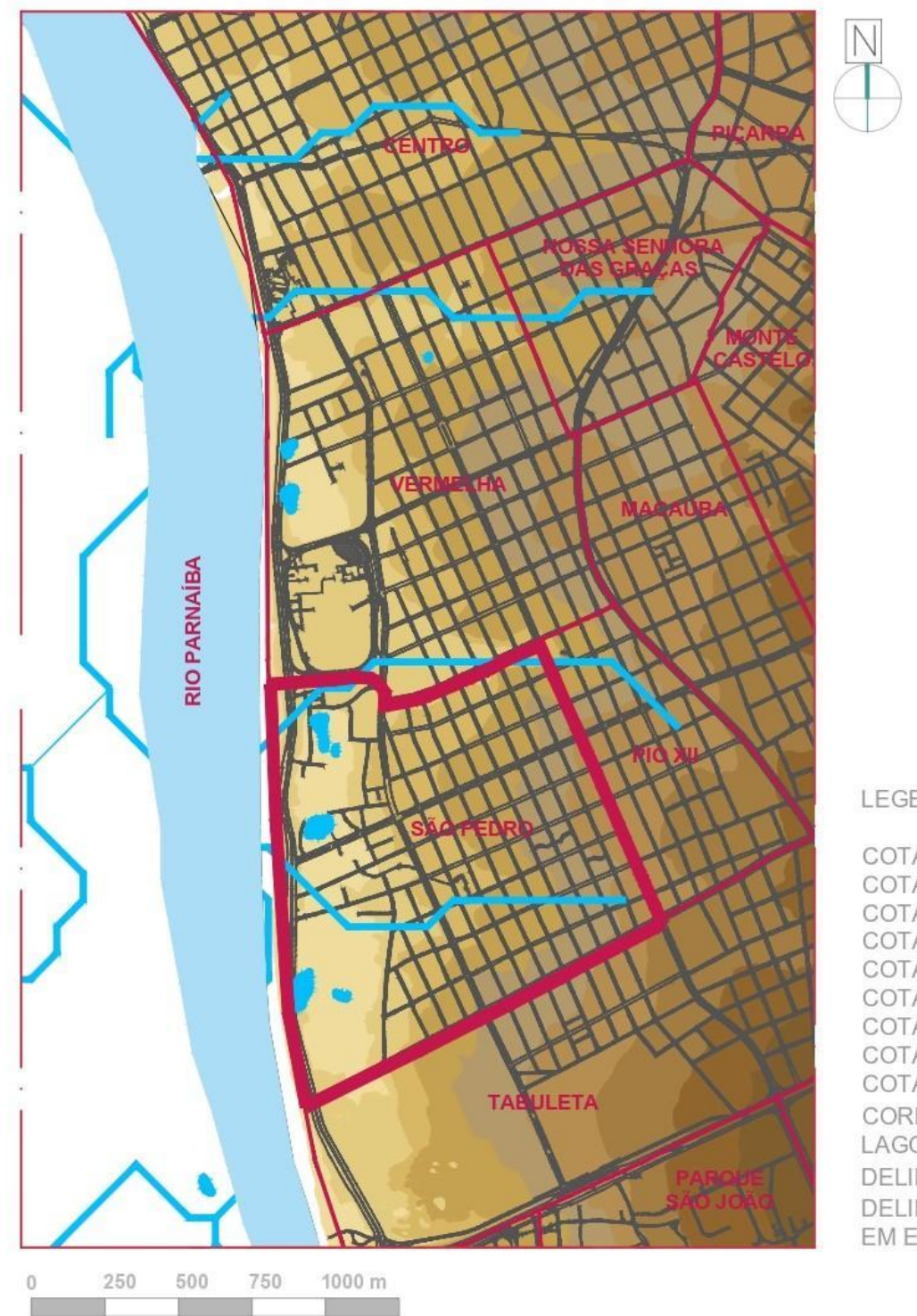

LEGENDA:

COTA DE NIVEL $95 \mathrm{~m}$.

COTA DE NIVEL $90 \mathrm{~m}$

COTA DE NIVEL $85 \mathrm{~m}$.

COTA DE NIVEL $80 \mathrm{~m}$

COTA DE NIVEL $75 \mathrm{~m}$.

COTA DE NIVEL $70 \mathrm{~m}$.

COTA DE NIVEL $65 \mathrm{~m}$.

COTA DE NIVEL $60 \mathrm{~m}$.

COTA DE NIVEL 55m.

CORPOS D'ÁGUA.

LAGOAS.

DELIMITAÇÃO DOS BAIRROS.

DELIMITAÇÃO DO BAIRRO

EM ESTUDO.

Fonte: PESSOA (2019) editado pelas autoras (2019)

\subsection{O zoneamento urbano e os corpos d'água}

No que se refere ao impacto das leis municipais de uso e ocupação do solo na drenagem urbana do bairro estudado, destacam-se a Lei Municipal n 3.560, de 20 de outubro de 2006, que "define as diretrizes para o uso do solo urbano do Município e dá outras providências" (TERESINA, 2006, p.10) e a Lei Municipal n 4. 724, de 3 de julho de 2015, que "define as diretrizes para regulamentação relativa a controle dos impactos de drenagem urbana de novos empreendimentos $e$ inundações ribeirinhas, na drenagem pluvial pública e dá outras providências" (TERESINA, 2015, p.2). 
A Lei Municipal $n^{\circ}$ 3.560/2006 define as diretrizes de uso do solo, apresentando em seu anexo 07 o mapa de zoneamento urbano da capital. Entretanto, este sofreu uma série de modificações pontuais no decorrer desses 12 anos, sendo que a maior parte delas refere-se a modificações das delimitações das diversas zonas que norteiam o uso do solo urbano. Dessa forma, para a análise do zoneamento urbano nesta pesquisa, utilizou-se como referência o mapa de zoneamento urbano disponibilizado pela SEMPLAN (2017) e atualizado em outubro de 2017.

A Figura 6 apresenta o recorte do mapa de zoneamento urbano e nele foram sobrepostos os corpos d'água delimitados pelo Plano Diretor de Drenagem Urbana de Teresina (2010). Analisando a Figura 6, pode-se perceber que os cursos d'águas intermitentes e as lagoas naturais, responsáveis pela drenagem natural das diversas sub-bacias urbanas que compõem o território analisado, não foram considerados no zoneamento. No entanto, de acordo com a Lei Municipal $n^{\circ} 4.724 / 2015$, as margens dos corpos d'água, tanto permanente quanto intermitentes - e das lagoas naturais -, devem ser consideradas áreas de preservação ambiental permanente (TERESINA, 2015).

Figura 6 - Zoneamento urbano e corpos d'água

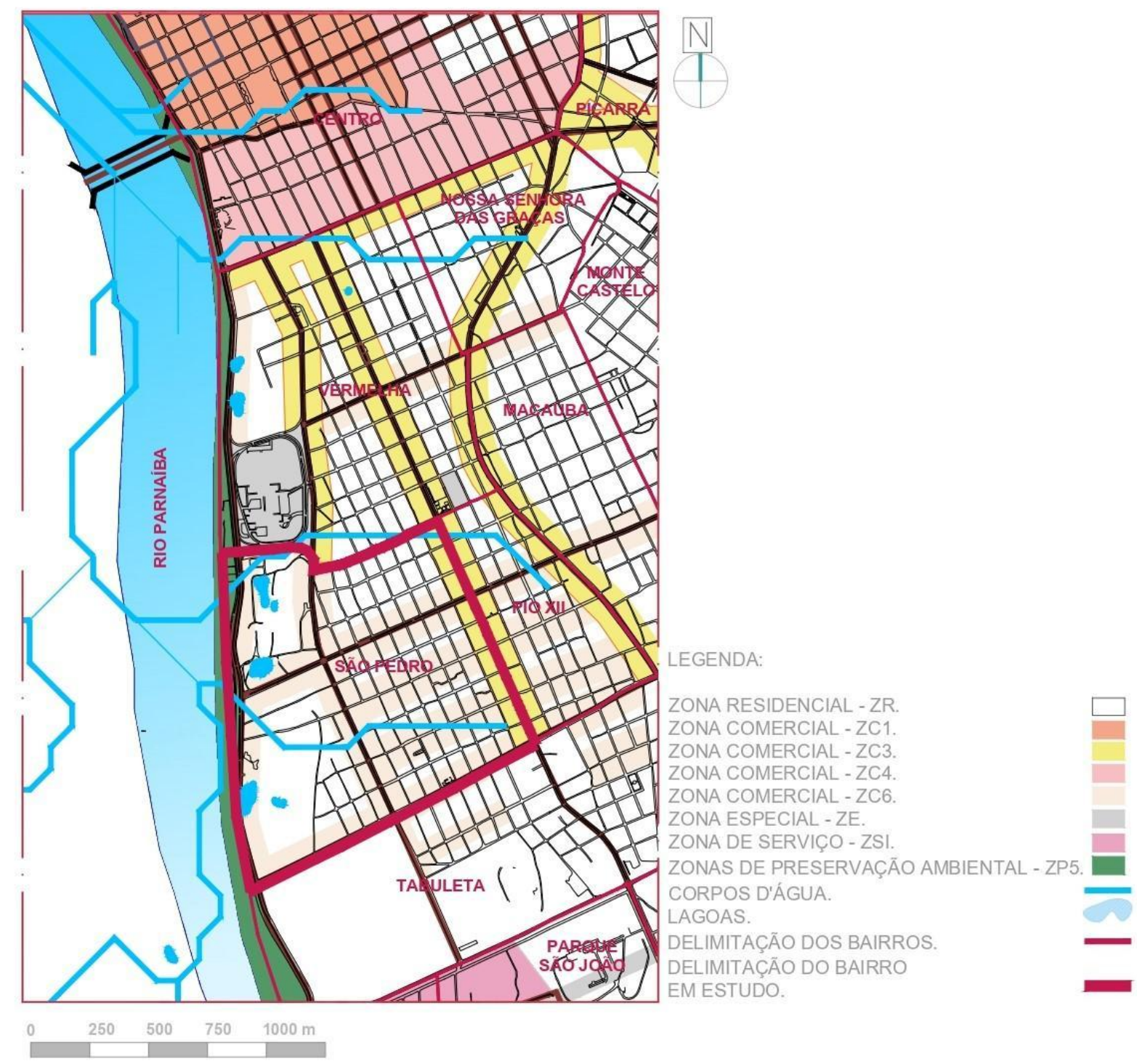

Fonte: PESSOA (2019) editado pelas autoras (2019) 


\section{CONCLUSÕES}

Diante das análises realizadas, fica evidenciado o impacto negativo do processo de urbanização sobre a drenagem urbana na área sob estudo, que desconsidera as características naturais do território, como a presença de corpos d'água e a topografia e acaba por inviabilizar o processo de drenagem natural. Dessa forma, destaca-se que as enchentes periódicas vivenciadas pelos moradores do Bairro São Pedro, não são fatalidades, mas sim resultado de uma série de negligências por parte dos agentes produtores do espaço urbano, quer públicos quer privados.

\section{REFERÊNCIAS}

FAÇANHA, A. C. A Evolução Urbana de Teresina: Agentes, Processos e Formas Espaciais da Cidade. 1998. 157p. Dissertação (Mestrado em Geografia) - Universidade Federal de Pernambuco, Recife, 1998.

FORTES CHUVAS ALAGAM casas e causam estragos em bairros de Teresina. Meio Norte. 2018. Disponível em: https://www.meionorte.com/noticias/fortes-chuvas-alagam-casas-e-causamestragos-em-bairros-de-teresina-334862. Acesso em: 4 abr. 2019.

FORTE CHUVA CAI em Teresina e trás transtornos e alagamento em alguns pontos da cidade. Estado do Piauí. 2019. Disponível em: http://www.estadopiaui.com/noticia/4023/forte-chuvacai-em-teresina-e-trs-transtornos-e-alagamento-em-alguns-pontos-da-cidade. Acesso em: 4 abr. 2019.

LIMA, I. M. M. F.; Teresina: Urbanização e meio ambiente. Scientia et Spes. Revista do Instituto Camillo Filho. Teresina: v. 1, n. 2, p. 181-206, 2002b.

MORADORES DO BAIRRO São Pedro ficam ilhados por conta da chuva do final de semana. G1. 2014. Disponível em: http://gl.globo.com/pi/piaui/bom-diapiaui/videos/t/edicoes/v/moradores-do-bairro-sao-pedro-ficam-ilhados-por-conta-dachuva-do-fim-de-semana/3152593/. Acesso em: 4 abr. 2019.

PESSOA, T. M. Teresina, uma cidade entre rios: estudo da gestão das águas pluviais na zona sul. 2019. 198p. Dissertação (Mestrado em Arquitetura e Urbanismo) - Universidade Federal da Bahia, Salvador, 2019.

POMPEU, C. A. Drenagem Urbana Sustentável. Revista Brasileira de Recursos Hídricos, Porto Alegre, v. 5, n. 1, p. 15-23. 2011. Disponível em:

https://www.abrh.org.br/SGCv3/index.php?PUB=1\&ID=46\&SUMARIO=656. Acesso em: 21 nov. 2017.

SEMPLAN. Teresina, aspectos e características: Perfil 1993. Teresina: Prefeitura Municipal de Teresina, 1993. $187 \mathrm{p}$.

SEMPLAN. Divisão dos Bairros de Teresina. Teresina: Prefeitura Municipal de Teresina, 2013. 1p. SEMPLAN. Caracterização do Município. Teresina: Prefeitura Municipal de Teresina, 2015. 11 p.

SEMPLAN. Mapa de Zoneamento Urbano. Teresina: Prefeitura Municipal de Teresina, 2017. 1p.

SILVEIRA, A. L. R. C. Parâmetros bioclimáticos para avaliação de conjuntos habitacionais na região tropical subúmida do Brasil. 2007. 312p. Tese (Doutorado em Arquitetura e Urbanismo) - Universidade de Brasília, Brasília, 2007.

SILVEIRA, A. L. R. C.; CARVALHO, R. M.; PESSOA, T. M. A gestão do uso e ocupação do solo e o controle das enchentes. In: CONGRESSO LUSO-BRASILEIRO PARA O PLANEJAMENTO 
URBANO, REGIONAL, INTEGRADO, SUSTENTÁVEL, 17., 2016, Maceió. Anais [...]. Maceió: UFAL, 2016. Disponível em: http://www.fau.ufal.br/evento/pluris2016/files/Tema\%204\%20-

\%20Planejamento\%20Regional\%20e\%20Urbano/Paper1273.pdf. Acesso em: 30 out. 2016.

SOUZA, V. C. B. Gestão da Drenagem Urbana no Brasil: Desafios para a sustentabilidade.

Revista Eletrônica de Gestão e Tecnologias Ambientais, Salvador, v. 1, n. 1, p. 57-72. 2017. Disponível em: http://dx.doi.org/10.17565/gesta.vli1.7105. Acesso em: 12 jan. 2018.

SOUZA, P. G. C. Guilherme Mûller e a invenção visual de Teresina. 1 ed. Teresina: Nova Aliança, 2017.

TAVANTI, D. R.; BARBASSA, A. P. Contribuições do planejamento urbano ás questões hidrológicas e ambientais. In: CONGRESSO LUSO-BRASILEIRO PARA O PLANEJAMENTO URBANO, REGIONAL, INTEGRADO, SUSTENTÁVEL, 4., 2010, Faro. Anais [...]. São Carlos: USP, 2010. Disponível em: http://pluris2010.civil.uminho.pt/Actas/PDF/Paper161.pdf. Acesso em: 12 out. 2016.

TAVANTI, D. R. Desenvolvimento de baixo impacto aplicado ao processo de planejamento urbano. 2009. 151 p. Dissertação (Mestrado em Engenharia Urbana) - Universidade Federal de São Carlos, São Carlos, 2011.

TERESINA, Plano Diretor de Drenagem Urbana de Teresina. Secretaria Municipal de Planejamento e Coordenação. Teresina: Concremat Engenharia, 2010. Disponível em: http://semplan.teresina.pi.gov.br/saneamento-downloads/. Acesso em: 30 ago 2016.

TERESINA, Lei complementar $n^{\circ} 3.560$, de 20 de outubro de 2006. Define as diretrizes para o uso do solo urbano do Município e dá outras providências. Diário Oficial do Município de Teresina. Poder Legislativo, Teresina, Pl, 27 de outubro de 2006.

TERESINA, Lei complementar $n^{\circ} .4 .724$, de 3 de junho de 2015. Define as diretrizes para regulação relativa a controle dos impactos da drenagem urbana de novos empreendimentos e inundações ribeirinhas, na drenagem pluvial pública e dá outras providências. Diário Oficial do Município de Teresina, Poder Executivo, Teresina, Pl, 12 jun. 2015.

TUCCl, C. E. M. Gestão de águas pluviais urbanas. 1 ed. Brasília: Ministério das Cidades. 2006. Disponível em:

http://www.capacidades.gov.br/media/doc/acervo/06906898a257ceb3ec8687675e9e36c8. pdf. Acesso em: 12 out. 2016.

VIEIRA, D. M.; TEIXEIRA, P. W. G. N.; LOPES, W. G. R. Identificação dos Usos e Ocupações do Solo nas Áreas de preservação permanentes do Rio Poti e sua compatibilidade legal no perímetro urbano de Teresina, Piauí - Brasil. In: ENCONTRO DA SOCIEDADE BRASILEIRA DE ECONOMIA ECOLÓGICA, 2007, Fortaleza. Anais [...]. Fortaleza: UNIFOR, 2007. Disponível em: https://pt.scribd.com/document/79057340/Identificacao-Dos-Usos-e-Ocupacao. Acesso em: 10 maio 2018. 